$\begin{gathered}\text { EPiC Series in Built Environment } \\ \text { Volume 2, 2021, Pages 578-586 }\end{gathered}$
ASC 2021. 57th Annual Associated Schools
of Construction International Conference

\title{
Implementing a Project-Based Learning Approach in the Pandemic
}

\author{
Adam Bogedain, M.S. and Kasim Korkmaz, Ph.D. \\ Eastern Michigan University \\ Ypsilanti, MI
}

\begin{abstract}
When the pandemic hit the United States shores in early 2020, higher education institutions started to revise their instructional delivery methods accordingly in such a short period. It was a challenge for instructors to find a way to offer classes in a remote version online using asynchronous and synchronous digital platforms. The problem occurs when some classes focus on a hands-on approach that needs to be utilized in disciplines like Construction Management (CM). The question becomes, 'how to offer an effective and safe learning environment?' This paper presents a new approach to a CM class with a lab component that was created during the pandemic. 'Construction Systems' is a core CM course that students need, and it was assigned to be offered with a face-toface element during the summer term of 2020. Detailed instructional planning was carried out in implementing a Project-Based Learning (PBL) approach considering student health and safety using educational technologies. In the paper, details of the planning for the PBL, implementation process, creating an active learning environment are detailed based on a real experience. As primary research findings, a new PBL approach was introduced and tested during the pandemic, and the results are promising. Therefore, this approach can be used by other CM programs around the country for future necessities.
\end{abstract}

Key Words: Flipped-Classroom, CM Education, Active Learning Environment, Project-Based Learning (PBL), Pandemic

\section{Introduction}

Higher education institutions needed to revise their course delivery methods during the pandemic to offer the best education possible given the circumstances. At the beginning of the pandemic period, it was thought that would be a short period of time, but unfortunately, that was not the case. In our institution, the winter semester of 2020 finished classes with a mixture of asynchronous and synchronous online courses. Any of the face-to-face course laboratory elements had to find a way to be remote. On the lighter side, during the winter semester, the shift to entirely online happened within the last month of the semester, where much of the lab work was completed before the lockdown. The problem that arose was the perceived short-lived virus carried into the summer term for colleges. The majority of the CM programs have courses with an in-person element to fulfill the student's learning outcomes and the accreditation requirements that may come into play. In our institution, a plan was 
devised to offer the 'Construction Systems' class in the summer term in 2020 as a hybrid with minimal synchronous video meetings, then asynchronous approach, and plenty of face-to-face outside socially distanced projects. The course was needed for $\mathrm{CM}$ and interior design students that required the course for graduation. The course covers the core elements of construction in lectures, but the course's critical component is actually using the construction industry tools to build projects. The class was altered to allow the lectures to be conducted remotely, which will be explained in more detail in the following sections. The primary component is the hands-on activities students can engage in, which were kept to an outdoor environment. With all the pandemic challenges, the students were excited to be a part of the class. The literature addresses the challenges the university and classes faced, which impacted how courses that had a face-to-face component were conducted. The present research work primarily focuses on a real experience to explain how the instructional planning for implementing the Project-Based Learning (PBL) approach in an active learning environment was evolved using educational technologies considering students' health and safety.

\section{Background}

The pandemic period brought new educational concepts that started in early 2020 . When the majority of the institutions went into a new era, there were so many variables that impacted their academic styles and techniques. For the most part, they were forced to conduct online learning. Online learning takes various forms that play into education, from the asynchronous to the synchronous. Many educational, technological tools can be utilized in learning, but many classes with a laboratory component can face a fully online learning challenge. Upon diligent searching, in areas related to construction management such as engineering, no study discussed teaching face-to-face in the pandemic. Beyond video conferencing, simulations, Augmented Reality (AR) and Virtual Reality (VR) are some deliverables the medical industry have implemented even before the pandemic period that has been an essential tool in student learning (Iwanaga, Loukas, Dumont, \& Tubbs, 2020). It was found that comparing the traditional tools to digital models, the students scored similar on assessments. On the other hand, the study found the conventional method allowed more use of teamwork.

Basilaia and Kvavadze (2020) published a paper related to the transition period in the pandemic. This paper presents the difficulties and challenges specifically in Georgia. Basilaia et al. (2020) analyzed the educational capabilities of students, which could effectively and considerably succeed the learning outcomes. In most cases, face-to-face classes are giving a competitive environment comparing to online courses. Various research shows that online learning performance is slightly better than in faceto-face courses (Liu, 2010; Ladyshewsky, 2004; Iftakhar, 2016). Some research works stated that if students opt for online education, they do not have to commute, which reduces the risk of infection (Nagrale, 2013). Another study explained that students seeking to enroll in an online program need to invest in various equipment, including a computer, webcam, and stable internet connection (Brown, 2017). Therefore, there are a variety of opinions for online and face-to-face classes. According to some research results, the programs with all learning components would give students a better learning environment (Korkmaz, \& Toraman, 2020).

The existing research works presently available techniques for CM programs. Various research presents a different approach utilizing tools such as Building Information Modeling (BIM) and threedimensional scanning technologies relating to AR and VR (Agostinelli, 2019; Jones \& Sharma, 2020). These methodologies for construction management classes may have a significant impact on pre-class learning before the laboratory element. Pre-class learning is considered a passive learning element, 
while in-class learning is active learning based on the flipped-classroom pedagogical delivery method (Chou \& Chuang, 2016). The flipped-classroom used for most of the Construction Systems class brings the lecture to asynchronous passive learning using videos with periodic assessments, and the in-class learning for laboratory projects then becomes an active learning environment. The pre-class videos were included to allow more laboratory time to be discussed, as synchronous video conferencing sacrificed too much valuable hands-on class time available. According to Srivastava et al. (2020), "video conferencing application is a feasible way of online teaching. However, it cannot be labeled as an alternative or replacement of the physical teaching" (p. 767). There is a need to combine pedagogical methods to make a course successful. In the environment of teaching during the pandemic period, there is a need to be flexible, with a modular outlook on course components as the school guidelines may change periodically.

\section{University and Course Preparation}

The pandemic played a significant role in what courses were allowed to run face-to-face in the summer term in 2020. Besides Construction Systems, another course, Surveying, was offered in a similar respect during the summer term. Only $0.1 \%$ of the offered courses were planned with a faceto-face element in the entire university. Two construction management courses were delivered with a face-to-face component in summer term 2020 out of around 1300 classes in the whole university. Other courses delivered with a face-to-face element were science and healthcare that need a hands-on approach like the Construction Management program. The total number of classes offered in the summer term of 2020 may seem like a large number. For comparison, in the summer term in 2019, around 2600 courses ran, which shows the pandemic period's strong impact.

Before any courses with a face-to-face element could be run, there was much planning involved on the university's part. Faculty and students were kept informed by the university and regularly provoked safe return to campus policies. The first step was to complete a virtual training module for faculty teaching courses on campus, followed by a face-to-face meeting with health and safety personnel. The health and safety personnel were coordinating the classes with face-to-face elements. A website was designed to keep campus-wide communications.

\section{Course Planning}

Before the pandemic, the 'Construction Systems' class was conducted face-to-face, with half of the allotted class time for traditional lectures and the other half as laboratory projects. With the recent changes needed in the early part of the summer term, the faculty was directed to start the first week with fully online material. As a result, the first week of the semester was conducted with the traditional lecture content in a video conferencing method. The second week of class was to have a virtual meeting and a face-to-face lab activity. After the second week, it was found that the synchronous online sessions once a week limited the face-to-face elements to one meeting per week. With permission from the university, all class periods would be face-to-face as a laboratory element. The lectures were moved into a virtual pre-class mode using the flipped-classroom approach. The flipped-classroom approach promotes student-centered learning and engagement, shifting away from the teacher-centered lecture learning environment that has been a traditional delivery model (Long, Cummins, \& Waugh, 2017). In recent years, this practice had gained popularity in the educational community due to the increased engagement that can arise out of the classroom. Numerous studies 
outlined the advantages and disadvantages of the flipped-classroom in various disciplines. The preclass material review and assessments may be passive initially but lead to active learning in the classroom. All in-class time focuses on active learning and engagement, which then becomes the focus. According to Bhat, Raju, Bhat, and D'Souza (2020) and other researchers on the flippedclassroom approach, this delivery methods' primary goal is to create as much active learning as possible compared to passive learning. Active learning increases engagement and knowledge retention, especially in occupations that involve projects and collaboration, such as construction management and engineering.

The flipped-classroom is not new for the faculty in our program. 'Computer Applications for Construction' class has been utilizing this pedagogical method since 2017 upon developing the course. The flipped-classroom moves the passive lectures online, which allows for active PBL in-class. The critical difference between the computer applications class and the construction systems class is the tools utilized in constructing projects. Students construct digitally in the computer course, whereas in the construction systems class, they use physical construction tools. To plan 'Construction Systems' during the pandemic, a solid instructional model was utilized as it was in developing 'Computer Applications for Construction.' The instructional model, Analysis, Design, Development, Implementation, and Evaluation (ADDIE), was implemented. ADDIE is a process used in instructional design to facilitate course and curriculum development (Lee, Lim, \& Kim, 2017). ADDIE was developed in the 1970s at Florida State University's Center for Educational Technology in conjunction with a military training program. The ADDIE model is how this course was planned for the pre-class and the hands-on in-class activities. The ADDIE model's five steps approach, as illustrated in Figure 1, is simple; as one step is completed, the next step is to follow, as explained in the following sections.

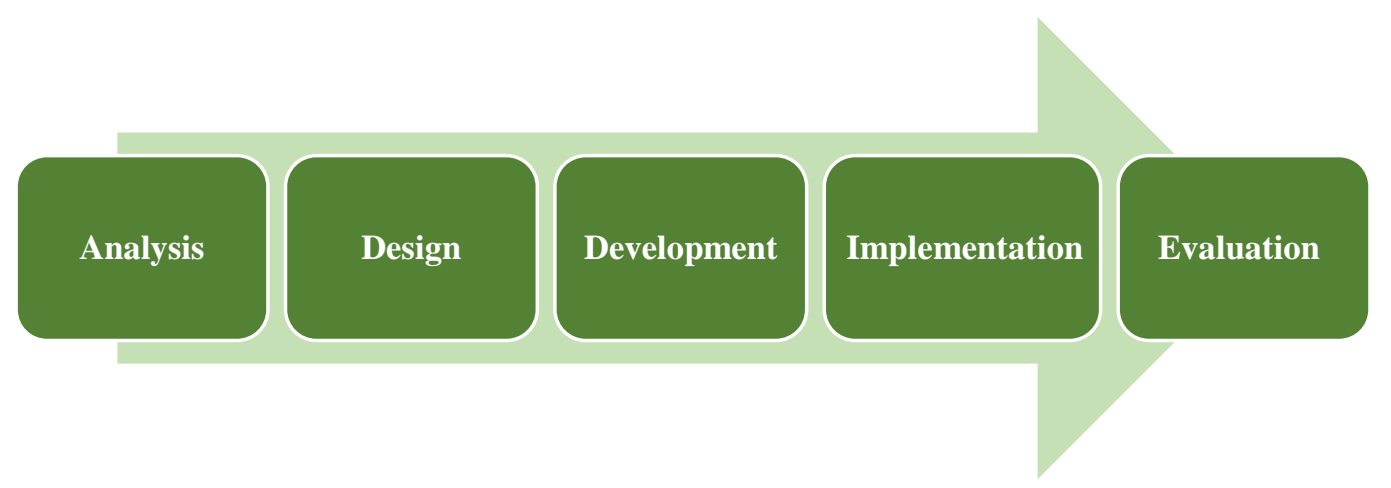

Figure 1. ADDIE Model Process 
To analyze what is needed for a course, first and foremost, there is a need to comply with the CDC guidelines. The course was scheduled to meet twice a week on Tuesdays and Thursdays. The first week all classes were required to be totally virtual, and as a result, the first week of the course ran synchronous online meetings for the class, followed by a quiz to knowledge check for material understanding. The remaining weeks would have the pre-class component to be asynchronous microlearning videos, followed by pre-class assessments. Micro-learning breaks up the videos into the smallest learning element with video lengths in the 5 to 10 minute range. It is better to have many short videos that equal an hour compared to one continuous one-hour video. Essentially, this method can be thought of as the building blocks of learning. Constructing a video structure like a Work Breakdown Structure (WBS) used in project management. Scholtenhuis, Vahdatikhaki, and Rouwenhorst (2020) found a practical use of multiple micro-learning videos kept to a 5 to 10 minute range. It would have been possible to offer one-night synchronous Zoom meetings, while the other night, face-to-face. The problem would be that a four-hour-long lecture would be challenging for students to focus and concentrate at a single meeting period in a week, and material retention would not be favorable to student learning. In the traditional classes, the students would have lectures followed by lab exercises at each meeting.

\section{Design of the Course}

The first week of the class was a long, nearly four-hour lecture for each meeting. It was used to gauge the student's possible interest in utilizing a full flipped-classroom approach by moving the lectures to an entirely asynchronous mode. The students were not officially surveyed, but there was an overwhelming response to using videos for pre-class learning in an asynchronous manner, so the students would have more class time to work on projects. After the second week of class, many micro-learning videos would be required for students to review, followed by assessments in the Learning Management System (LMS). The course would also offer two examinations in the LMS for mid-term and final assessments.

The challenge then became what projects to offer and how to proceed with the students. Traditionally the course offered laboratory projects on concrete, masonry, light wood framing, and student mock-up projects, etc. We created this opportunity to start construction on a gazebo service project off-campus. The CM program has completed two gazebo service projects in the past. Therefore, there is a familiarity with gazebo's in the program. The program faculty knew the steps and arrangements. According to previous experiences, it was known that the gazebo would not be completed during the summer term, and the fall semester would work on it as well. Besides the gazebo project, the students would also work socially distanced in two groups on collaborative mock-up projects.

For the mock-up project assignment, the students would be required to design, price, construct and present the completed project. After the mock-up project, the gazebo was the key project, and the design of the project is seen in Figure 2. The project requirement includes around $200 \mathrm{ft}^{2}$ covered gazebo with wood construction. The structure will be built on the western side of the existing parking lot, as identified in Figure 3. The site has a relatively flat surface at elevation $967 \mathrm{ft}$ above sea level with an eye-level of $1998 \mathrm{ft}$. 


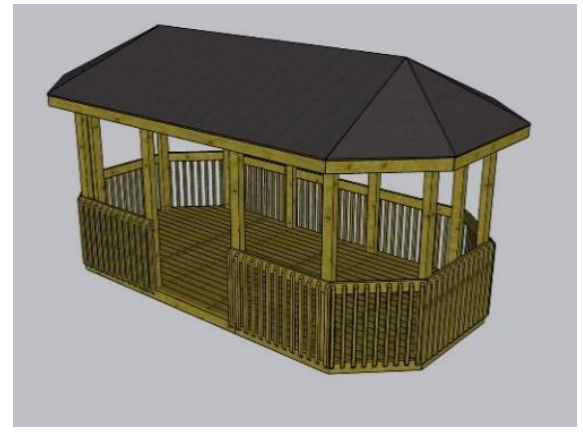

Figure 2. Model of Gazebo Design

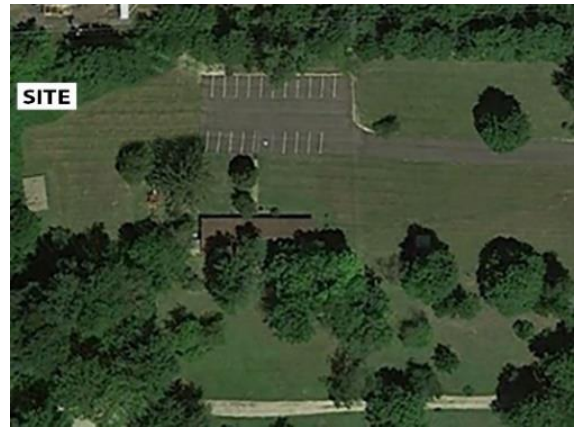

Figure 3. Aerial View of Project Site

\section{Development of the Course}

The traditional lecture material was utilized from previous years, but they were broken down into micro-learning elements. The lecture material was posted in the LMS with the videos. Students were required to complete a pre-class assessment before the start of class. Baytiyeh and Naja (2017) found that pre-class assessments were crucial for in-class participation. Pre-class assessments may be as simple as a few points that give the students an incentive and holds them accountable for their passive learning. A mid-term examination and final examination covered the post-class knowledge.

The mock-up projects are critical for students to have a personal connection to the class, which is why the mock-up projects traditionally were completed in mini-stages throughout the semester, and final construction were completed near the end of the semester. With the unknowns at the time, and if the course would still keep the face-to-face element for the rest of the semester, it was planned to have the students complete their projects within the first few weeks of class. The gazebo project on an offsite location would follow, allowing no inside activities. As we look through the first three steps of the ADDIE model, there was a significant amount of communication from the university, and the class strived to follow suit with any new developments as implementation approaches of the course.

\section{Implementation of the Course}

The pre-class material and assessment were implemented for the course, and the examination material was to be completed by the instructor before the class went live. The students still have one full week of synchronous learning from Zoom meetings to prepare for the course. Students were required to wear a mask, Cut Level-2 or better gloves, safety glasses, close-toed shoes, and a hard hat if overhead work were being conducted for all lab activities. There have been many theories on the use of gloves during the pandemic. Many commercial job sites have a $100 \%$ glove policy, so health and safety supported the decision for the construction management program. The mock-up project was put at the forefront. Since there was no weather resistance during the summer months, it was ideal to move the construction tables out of the construction lab and into the bigger space for students to work on their mock-up projects on campus, as seen in Figures 4 and 5. The students were only be allowed to access the lab for materials or to cut materials on tools affixed in the lab. The open-air and no lab access was a perfect project for the summer term during the pandemic, as seen in Figures 6 and 7. 


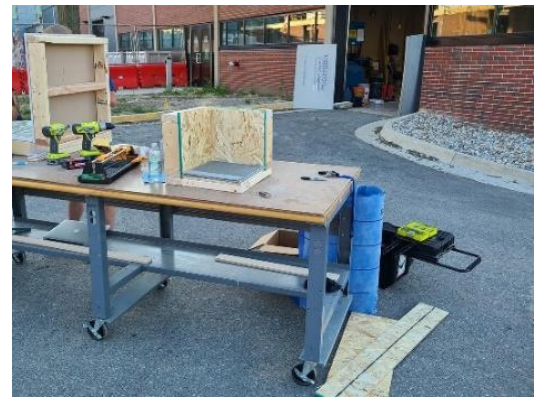

Figure 4. Mock-ups Outside CM Lab

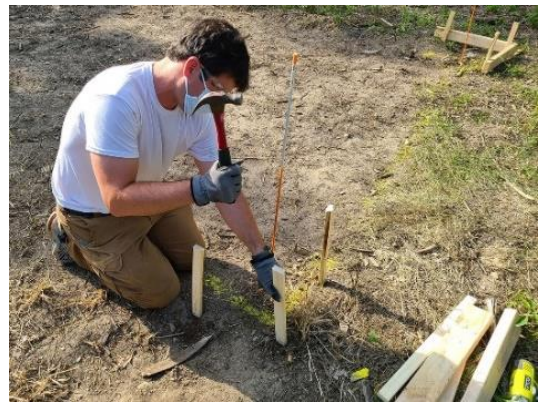

Figure 6. Installing Batter Boards

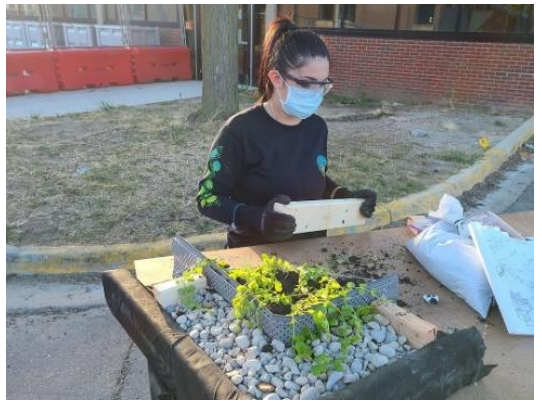

Figure 5. Student Working on Mock-up

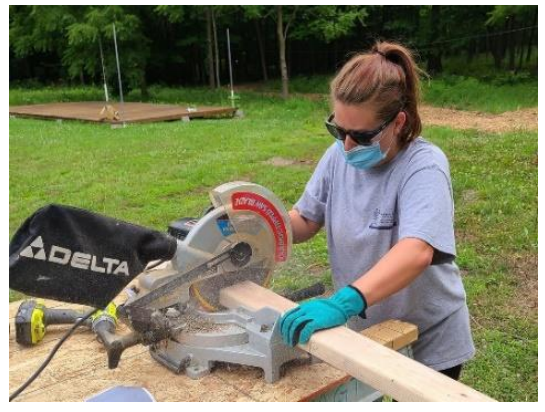

Figure 7. Cutting for Batter Boards

\section{Evaluation and Findings}

The summer term in the 2020 semester was different in evaluating the instructional model compared to prior semesters. The course was being evaluated continuously. The pre-class, in-class, and postclass materials were considered as an ongoing process through the summer term. The students, based on the pre-class assessments, reviewed the pre-class micro-learning videos. Additionally, the scores were generally in the $90 \%$ range for the examinations. No single student contracted with the requirements during the class. Everyone had a collaborative learning experience on the mock-up projects. The gazebo project offered a positive perspective on the semester to be considered a success, given the conditions. Student evaluations were found on the positive side, represents that the students have been happy to have the opportunity to take a hands-on course during the pandemic period. The students learned about differing site conduction with the gazebo. A previous structure was located on the site, which seems to be the remnants of an old barn, so the placement of posts in the concrete footings took an extra week or more than expected. During the class, some equipment was rented, which the students were explained was an additional cost associated that may not be typically realized in the estimate. Hence, students learned a valuable lesson on construction uncertainties. The primary objective was to safely run the course while learning and working together. In the future, qualitative and quantitative data will be collected on the student's official perspectives in utilizing the flippedclassroom in a class such as the 'Construction Systems' class ran during the pandemic. In the meantime, Figures 8 and 9 illustrate the end of summer 2020 semester instructor and course evaluations. 


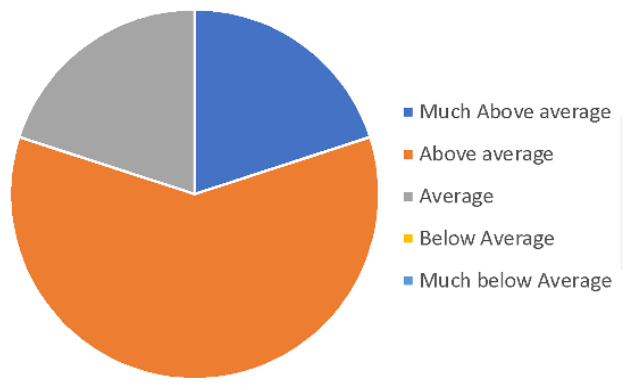

Figure 8. Instructor Evaluation

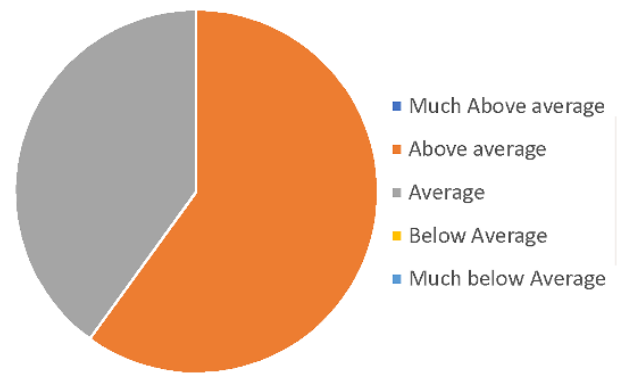

Figure 9. Course Evaluation

\section{Conclusion}

The students that participated in the 'Construction Systems' class in Summer 2020 found that the faceto-face element is key to active engagement with their peers. The challenge was having students attend to pre-class material. Pre-class assessments show a profound effect on making sure students are ready for in-class projects and collaboration. The class outcome was based on mock-up projects and the core gazebo project that would meet the course's learning objectives during the pandemic. We initiated the gazebo project because it was an ideal way to keep students outside and socially distanced, which would not have been a concern in pre-pandemic times. Students completed setting posts in the concrete footings and roughed in the structure in the summer term, where they had a collaborative PBL experience. Essentially, the program developed a model of using PBL for service project opportunities that other universities could use as a guide in the future. The end of course evaluations reported that $80 \%$ of the students felt the effectiveness was above/much above average. Collaborative learning is a critical component to involve students in an active learning environment.

\section{References}

Agostinelli Jr, M. D. (2019). From distance education to online education: A review of the literature. Graduate Student Theses, Dissertations, \& Professional Papers. 11335. https://scholarworks.umt.edu/etd/11335.

Basilaia and Kvavadze (2020). Transition to online education in schools during a SARS-CoV-2 Coronavirus (COVID-19) pandemic in Georgia. Pedagogical Research, 5(4), em0060. https://doi.org/10.29333/pr/7937

Basilaia, G., Dgebuadze, M., Kantaria, M., \& Chokhonelidze, G. (2020) 'Replacing the classic learning form at universities as an immediate response to the COVID-19 virus infection in Georgia'. International Journal for Research in Applied Science \& Engineering Technology (IJRASET), 8(3), 101-108. https://doi.org/10.22214/ijraset.2020.3021

Baytiyeh., H. \& Naja, M.K. (2017). Students' perceptions of the flipped classroom model in an engineering course: A case study. European Journal of Engineering Education, 42(6), 1048 1061. https://doi.org/10.1080/03043797.2016.1252905 
Bhat, S., Raju, R., Bhat, S., \& D'Souza, R. (2020). Redefining quality in engineering education through the flipped classroom model. Procedia Computer Science, 172, 906-914. https://doi.org/10.1016/j.procs.2020.05.131

Brown, C. (2017). Advantages and disadvantages of distance learning. ezTalks. https://www.eztalks.com/elearning/advantages-and-disadvantages-of-distance-learning.html

Chou, K., \& Chuang, K. (2016). Building a cooperative learning environment in a flipped classroom. Academy of Educational Leadership Journal, 20(2), 8-15. http://ezproxy.emich.edu/login?url=https://www.proquest.com/docview/1826881345?

Iftakhar S. (2016). Google classroom: what works and how. Journal of Education and Social Sciences, 3(1), 12-18. https://www.jesoc.com/wp-content/uploads/2016/03/KC3_35.pdf

Iwanaga, J., Loukas, M., Dumont, A.S., \& Tubbs, R.S. (2020). A review of anatomy education during and after the COVID-19 pandemic: Revisiting traditional and modern methods to achieve future innovation. Clin Anat, 34, 108-114. https://doi.org/ 10.1002/ca.23655

Jones, K., \& Sharma, R. (2020). Reimagining a future for online learning in the post-COVID era. SSRN. http://dx.doi.org/10.2139/ssrn.3578310

Korkmaz, G. \& Toraman, C. (2020). Are we ready for the post-COVID-19 educational practice? An investigation into what educators think as to online learning. IJTES, 4(4), 293-309. https://doi.org/10.46328/ijtes.v4i4.110

Lee, J., Lim, C., \& Kim, H. (2017). Development of an instructional design model for flipped learning in higher education. Education Tech Research Dev, 65(2), 427-453. https://doi.org/10.1007/s11423-016-9502-1

Liu, C. H. (2010). The comparison of learning effectiveness between traditional face-to-face learning and e-learning among goal-oriented users. 6th ICDC\&MTA Conference 255-260 https://ieeexplore.ieee.org/document/5568694

Long, T., Cummins, J., \& Waugh, M. (2017). Use of the flipped classroom instructional model in higher education: Instructors' perspectives. Journal of Computing in Higher Education, 29(2), 179-200. http://dx.doi.org/10.1007/s12528-016-9119-8

Nagrale, P. (2013). Advantages and disadvantages of distance education. https://surejob.in/advantages-and-disadvantages-of-distance-education.html

Ladyshewsky, R. K. (2004). E-learning compared with face to face: Differences in the academic achievement of postgraduate business students. Australasian Journal of Educational Technology, 20(3), 316-336. https://doi.org/10.14742/ajet.1350

Scholtenhuis, L., Vahdatikhaki, F., \& Rouwenhorst, C. (2020). Flipped microlecture classes: satisfied learners and higher performance? European Journal of Engineering Education, 1-23. https://doi.org/10.1080/03043797.2020.1819961

Srivastava, V., Pandey, V., Tiwari, P., Patel, S., Ansari, M.A., \& Shukla, V.K. (2020). Utility of realtime online teaching during COVID era among surgery postgraduates. Indian Journal of Surgery, 82(5), 762-768. https://doi.org/10.1007/s12262-020-02592-2 